\title{
CrystEngComm
}

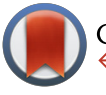

CrossMark \& click for updates

Cite this: CrystEngComm, 2016, 18, 5736

Received 4th April 2016,

Accepted 15th June 2016

www.rsc.org/crystengcomm
DOI: $10.1039 / c 6 c e 00764 c$

\section{Single-crystal to single-crystal conformational polymorphic transformation in tolbutamide at 313 K. Relation to other polymorphic transformations in tolbutamide and chlorpropamide $\dagger$}

\author{
T. N. Drebushchak, ${ }^{\star a b}$ V. A. Drebushchak, ${ }^{\text {bc }}$ N. A. Pankrushina ${ }^{d}$ and E. V. Boldyreva ${ }^{a}$
}

\begin{abstract}
Three polymorphs of tolbutamide ( ${ }^{L}$, II, and III) were studied using single-crystal X-ray diffraction, from 100 $\mathrm{K}$ to room temperature (forms II and III) and to $350 \mathrm{~K}$ (form I), and differential scanning calorimetry. The reversible transformation, $\mathrm{I}^{\mathrm{L}} \Leftrightarrow \mathrm{I}^{\mathrm{H}}$, was found to be of the single-crystal to single-crystal type and the structure of the high-temperature form $\left(\mathrm{I}^{\mathrm{H}}\right)$ was solved and refined. The structure of $\mathrm{I}^{\mathrm{H}}$ differs from that of $\mathrm{I}^{\mathrm{L}}$ only in the conformation of the molecule, with molecular arrangements being practically unchanged (isostructural conformational transformation). The transition takes place at $313 \mathrm{~K}$ with no sign of hysteresis. The volume change, $\Delta V / V$, across the reversible transformation $\mathrm{I}^{\mathrm{L}} \Leftrightarrow \mathrm{I}^{\mathrm{H}}$ was calculated and compared to those for the other conformational transformations. Two types of conformational polymorphic transformations (irreversible reconstructive and reversible isostructural) in tolbutamide and chlorpropamide were compared.
\end{abstract}

\section{Introduction}

Conformational polymorphism is common among organic crystals. ${ }^{1-3}$ Polymorphic transformations can be accompanied by a change in the geometry of molecules. If the two conformations correspond to two different local minima on the gas potential energy surface (gas-PES), one refers to this as conformational change; if the two conformations correspond to the same local minimum, this is termed conformational adjustment. ${ }^{1}$ One can consider two types of conformational polymorphic transformations (accompanied by a conformational change, not conformational adjustment): (1) transformations involving changes in molecular conformations only, with the packing of the molecules preserved (isostructural conformational transformations) and (2) transformations involving changes in both the conformations and packing of molecules, including, in particular, reconstruction of a hydrogen-bond network (reconstructive conformational trans-

\footnotetext{
${ }^{a}$ Institute of Solid State Chemistry and Mechanochemistry SB RAS, Kutateladze, 18, Novosibirsk, 630128, Russia. E-mail: tanya@xray.nsu.ru

${ }^{b}$ Novosibirsk State University, Pirogova, 2, Novosibirsk, 630090, Russia

${ }^{c}$ V. S. Sobolev Institute of Geology and Mineralogy SB RAS, Pr. Ak. Koptyuga, 3, Novosibirsk, 630090, Russia

${ }^{d} N$. N. Vorozhtsov Novosibirsk Institute of Organic Chemistry SB RAS, Pr. Ak. Lavrentieva, 9, Novosibirsk, 630090, Russia

$\dagger$ Electronic supplementary information (ESI) available: The unit cell parameters for polymorphs I, II, and III of tolbutamide (Table 1S). CCDC 1469769-1469773. For ESI and crystallographic data in CIF or other electronic format see DOI: 10.1039/c6ce00764c
}

formations). A transformation of the first type can proceed without fragmentation of a single crystal (a single-crystal to single-crystal transition). Two sulphonylurea derivatives used in the treatment of type 2 diabetes mellitus, tolbutamide ( $N$-[(butylamino)carbonyl]-4-methylbenzenesulfonamide) and chlorpropamide (4-chloro- $N$-(propylaminocarbonyl)benzenesulfonamide), provide examples of rich conformational polymorphism (molecular conformations are different in each of their polymorphs). ${ }^{4-18}$ All known polymorphs of tolbutamide and chlorpropamide contain identical

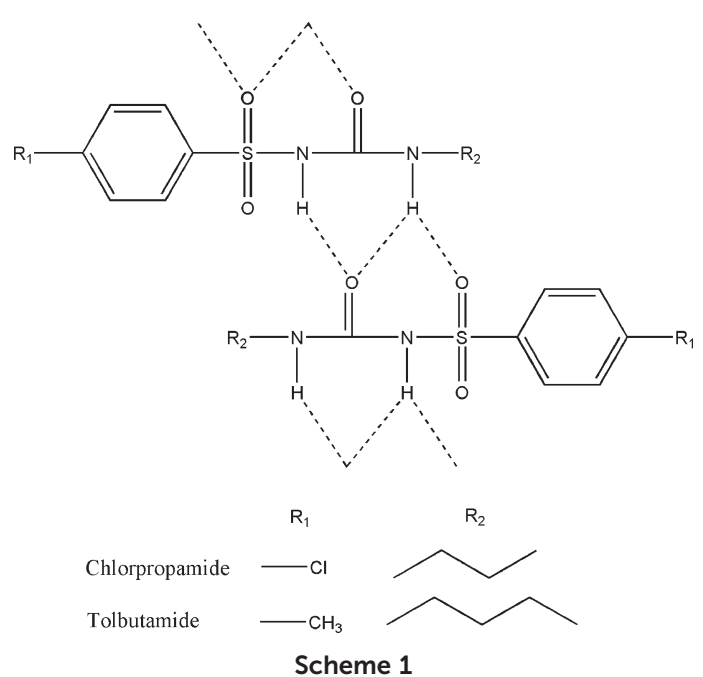


hydrogen-bond motifs, forming infinite chains of molecules of alternating orientation (Scheme 1). Bonded via their central parts, the head and tail regions of the molecules remain flexible. It is therefore not surprising that polymorphs differ mainly in the conformation of the alkyl tail and in the orientation of the benzene ring head.

On heating from room temperature, all polymorphs of the two sulphonylureas transform into their respective hightemperature forms (denoted $\varepsilon$ for chlorpropamide ${ }^{8}$ and $\mathrm{I}^{\mathrm{H}}$ for tolbutamide $\left.\mathrm{in}^{14,15}\right)$, each of which is stable up to their melting points. The crystal structure of $\varepsilon$-chlorpropamide has been known for a number of years. ${ }^{7}$ This high-temperature form, once obtained, can also be preserved at ambient temperature. ${ }^{6,7}$ The crystal structure of $\mathrm{I}^{\mathrm{H}}$ tolbutamide has remained undocumented to date (CSD version 5.36). ${ }^{20}$ The hightemperature polymorph of tolbutamide, contrary to that of chlorpropamide, has never been observed at room temperature. The $\mathrm{I}^{\mathrm{L}} \Leftrightarrow \mathrm{I}^{\mathrm{H}}$ transformation in tolbutamide is reversible, with the transition temperature close to $40^{\circ} \mathrm{C} .{ }^{14,15}$

Polymorphs of chlorpropamide behave differently during temperature variations. On cooling, $\beta$-chlorpropamide undergoes two reversible phase transitions. ${ }^{10}$ The second phase transition $\left(\beta^{\mathrm{II}} \Leftrightarrow \beta^{\mathrm{III}}\right)$ is related to a change in the conformation of the alkyl tail in $1 / 4$ of the molecules across the transition point. If cooled below room temperature, $\varepsilon$-chlorpropamide transforms into a different polymorph, $\varepsilon^{\prime}$, which differs only in the conformation of the molecule from the parent $\varepsilon$-chlorpropamide crystal structure. ${ }^{9}$ The $\alpha-, \gamma$-, and $\delta$-polymorphs do not undergo phase transitions on cooling. ${ }^{9,19}$ Form III of tolbutamide transforms reversibly into the form denoted as $\mathrm{III}^{2}$ between 100 and $150 \mathrm{~K}$ and is of the single-crystal to single-crystal type. ${ }^{17}$ The translation symmetry changes, since the conformation in every third molecule changes during the course of the transformation. The crystal structure of form $\mathrm{III}^{2}$ was also reported as being "a high $Z^{\prime}$ variation of form III". ${ }^{16}$ This polymorph was claimed to be the result of special crystallization conditions, although its crystal structure was also solved originally at $100 \mathrm{~K}$, i.e. below the phase transition point, and only after that - at ambient temperature.

The purpose of this work was to undertake a structural investigation of the three polymorphs of tolbutamide (I, II, and III) over a wide temperature range in order to fill in the gaps in the available structural data. We aimed to solve the crystal structure of the $\mathrm{I}^{\mathrm{H}}$ high-temperature form of tolbutamide, in order to clarify the nature of this reversible transformation in tolbutamide, as well as to compare the different types of conformational polymorphic transformations on cooling and heating in tolbutamide and chlorpropamide.

\section{Experimental}

Single crystals of three tolbutamide polymorphs were grown from solutions of tolbutamide (SIGMA) in different solvents: form I from ethyl acetate, form II from acetonitrile, and form III from a mixture of $\mathrm{MeOH}-\mathrm{H}_{2} \mathrm{O}(2: 1)$. The mixtures of three polymorphs often crystallised concomitantly. Single crystals suitable for X-ray diffraction were selected from the crystallized batches under a microscope.

Single-crystal X-ray diffraction was carried out using an Oxford Diffraction Gemini R Ultra diffractometer with a Ruby CCD detector ( $\mathrm{MoK}_{\alpha}$ radiation). A low-temperature Oxford Instruments Cryojet HT device was used for varying the temperature. CrysAlis software was used for data collection and processing. ${ }^{21}$ For polymorph $\mathrm{I}^{\mathrm{L}}$, unit-cell parameters were determined at temperatures from 100 to $350 \mathrm{~K}$, with temperature steps ranging from 10 to $25 \mathrm{~K}$. Data for structure solution and refinement were collected at 100, 200, 295, and 330 K. Crystal structures were solved by direct methods using $S H E L X S,{ }^{22}$ and refined on $F^{2}$ with all data using $S H E L X L^{23}$ with anisotropic thermal parameters for all non-hydrogen atoms. Hydrogen atoms were either located in the difference maps or were positioned geometrically and refined with a riding model. Additional restraints were imposed on the distances, and the anisotropic displacement parameters for the alkyl tails of tolbutamide molecules in the structures were refined at $330 \mathrm{~K}$, above the phase transition. At this temperature, the alkyl tails are disordered over two positions (Fig. 1). For polymorph I, all measurements were carried out with the same single crystal for all temperatures; this includes both the $\mathrm{I}^{\mathrm{L}}$ and $\mathrm{I}^{\mathrm{H}}$ forms. Selected crystallographic parameters, data collection and refinement details are summarized in Table 1.
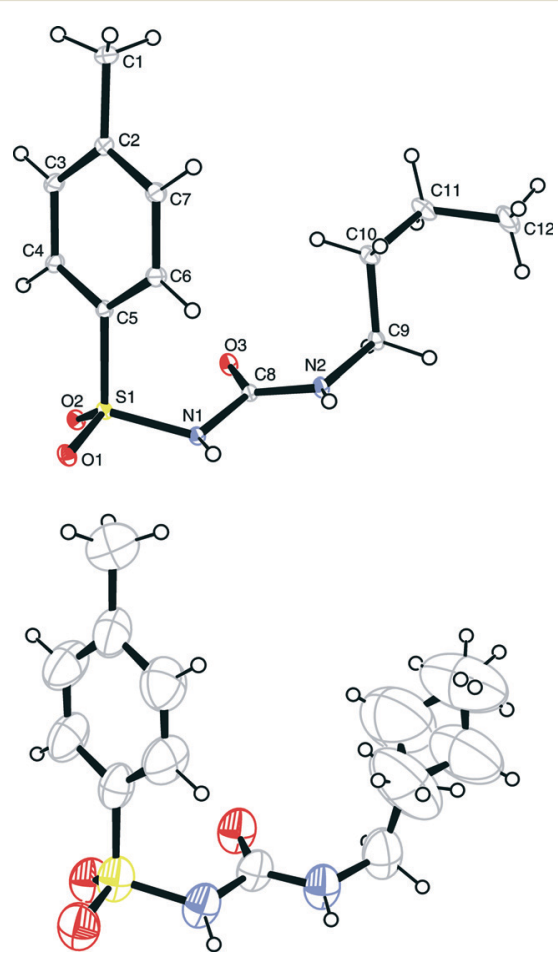

Fig. 1 The asymmetric unit of tolbutamide in form $\mathrm{I}^{\mathrm{L}}$ at $100 \mathrm{~K}$ (above) and in form $\mathrm{I}^{\mathrm{H}}$ at $330 \mathrm{~K}$ (below). Atom $\mathrm{C} 11$ in the alkyl tail of the molecule is disordered over two positions at $330 \mathrm{~K}$. Displacement ellipsoids are drawn at the $30 \%$ probability level. $\mathrm{H}$ atoms are shown with an arbitrary radius. 
Table 1 Crystallographic data and structure refinement details

\begin{tabular}{|c|c|c|c|c|c|}
\hline & Form $\mathrm{I}^{\mathrm{L}}$ & & & Form $\mathrm{I}^{\mathrm{H}}$ & Form II \\
\hline Formula & $\mathrm{C}_{12} \mathrm{H}_{18} \mathrm{~N}_{2} \mathrm{O}_{3} \mathrm{~S}$ & & & $\mathrm{C}_{12} \mathrm{H}_{18} \mathrm{~N}_{2} \mathrm{O}_{3} \mathrm{~S}$ & $\mathrm{C}_{12} \mathrm{H}_{18} \mathrm{~N}_{2} \mathrm{O}_{3} \mathrm{~S}$ \\
\hline Formula weight & 270.34 & & & 270.34 & 270.34 \\
\hline Crystal system & Orthorhombic & & & Orthorhombic & Monoclinic \\
\hline Space group & $\operatorname{Pna2}_{1}$ & & & $\operatorname{Pna2}_{1}$ & $P c$ \\
\hline$T / \mathrm{K}$ & 100 & 200 & 295 & 330 & 100 \\
\hline$a / \AA$ & $19.4331(3)$ & $19.7525(3)$ & $20.2133(6)$ & $20.7500(15)$ & $9.0256(2)$ \\
\hline$b / \AA$ & $7.8010(1)$ & $7.7998(1)$ & $7.8233(2)$ & $7.9160(7)$ & $17.1443(5)$ \\
\hline$c / \AA$ & $9.0277(1)$ & $9.0583(1)$ & $9.0717(2)$ & $9.0580(5)$ & $17.7904(5)$ \\
\hline$\beta / \circ$ & 90 & 90 & 90 & 90 & $94.268(3)$ \\
\hline$V / \AA^{3}$ & $1368.58(3)$ & $1395.57(3)$ & $1434.55(6)$ & $1487.8(2)$ & $2745.21(13)$ \\
\hline$Z$ & 4 & 4 & 4 & 4 & 8 \\
\hline$D_{\mathrm{c}} / \mathrm{g} \mathrm{cm}^{-3}$ & 1.312 & 1.287 & 1.252 & 1.207 & 1.308 \\
\hline$\mu(\mathrm{Mo} \mathrm{K} \alpha) / \mathrm{mm}^{-1}$ & 0.239 & 0.234 & 0.228 & 0.220 & 0.238 \\
\hline$\theta$ range $/^{\circ}$ & $3.35-36.32$ & $3.05-26.37$ & $3.29-26.35$ & $1.96-26.35$ & $3.10-26.37$ \\
\hline Measured reflections & 47528 & 17224 & 26312 & 5834 & 42260 \\
\hline Independent reflections & 6600 & 2857 & 2924 & 2781 & 11214 \\
\hline Reflections with $I>2 \sigma(I)$ & 6147 & 2741 & 2725 & 1609 & 8469 \\
\hline$R_{\text {int }}$ & 0.036 & 0.024 & 0.027 & 0.032 & 0.099 \\
\hline$R\left[F^{2}>2 \sigma\left(F^{2}\right)\right]$ & 0.028 & 0.027 & 0.040 & 0.057 & 0.063 \\
\hline $\mathrm{w} R\left(F^{2}\right)$ & 0.072 & 0.072 & 0.115 & 0.182 & 0.109 \\
\hline
\end{tabular}

Additionally, for the tolbutamide polymorphs, II and III, the data have been collected in the temperature range from ambient to $100 \mathrm{~K}$, with unit cell parameters refined with a step size of $25 \mathrm{~K}$. Data for tolbutamide III at three temperature points $(100,150$, and $295 \mathrm{~K})$ were reported previously ${ }^{17}$ and agreed with the results in the present work. The crystal structure of tolbutamide II at $295 \mathrm{~K}$ was refined under the assumption that one in four molecules in the asymmetric unit had a disordered alkyl tail, and thus agreed well with that reported in, ${ }^{15}$ where it was refined at $153 \mathrm{~K}$. We have also refined the crystal structure of tolbutamide II at $100 \mathrm{~K}$. A model with disorder suggested the occupancy of the second orientation of the alkyl tail below $20 \%$, without a significant improvement in the value of the $R$-factor. Since the second orientation was also rather close to the main one (conformer adjustment at the most), we have given preference to a model without disorder over two selected positions, but with high values of atomic displacement parameters in general, which is common for many structures with alkyl tails (see Table 1). The unit cell parameters for polymorphs I, II, and III for all temperatures are reported in Table S1 of the ESI. $\dagger$

The X-ray powder diffraction patterns were recorded on a STOE STADI-MP diffractometer ( $\mathrm{CuK}_{\alpha 1}$ radiation, curved Ge monochromator, transmission/Debye-Scherrer mode) with a high temperature attachment for capillaries.

The programs WinGX, ${ }^{24}$ ORTEP3 for Windows, ${ }^{25}$ WinXPOW, ${ }^{26}$ and Mercury ${ }^{27}$ were used for visualization and analysis.

DSC measurements of the $\mathrm{I}^{\mathrm{L}} \Leftrightarrow \mathrm{I}^{\mathrm{H}}$ transformation were carried out using a DSC-204 Netzsch. Standard aluminum crucibles $(25 \mu \mathrm{L})$, covered with a lid (but not sealed), were

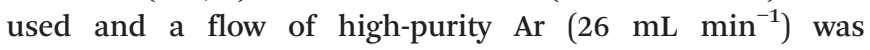
employed. Measurements were carried out in a single experiment, cycling heating and cooling at decreasing heating rates of $3,2,1,0.5$, and $0.2 \mathrm{~K} \mathrm{~min}^{-1}$. The sample (1.6 $\mathrm{mg}$ powder) was taken from a commercial batch of tolbutamide (SIGMA) without further purification or recrystallization. According to the X-ray powder diffraction pattern, this was the pure tolbutamide form, $\mathrm{I}^{\mathrm{L}}$.

\section{Results and discussion}

Phase transformation $\mathrm{I}^{\mathrm{L}} \Leftrightarrow \mathbf{I}^{\mathrm{H}}$, crystal structure of form $\mathrm{I}^{\mathrm{H}}$

The unit cell parameters and space group for form $\mathrm{I}^{\mathrm{H}}$ at 330 K (Table 1) agree well with those reported by Hasegawa $e t$ al. at $363 \mathrm{~K},{ }^{14}$ if thermal expansion is accounted for. In, ${ }^{14}$ the crystal structure of $\mathrm{I}^{\mathrm{H}}$ has been claimed to be solved from X-ray powder diffraction data. Unfortunately, the crystallographic information file and atomic coordinates were not reported by Hasegawa et al. ${ }^{14}$ and are missing from the Cambridge Structural Database. ${ }^{20}$ We have for the first time observed a single-crystal to single-crystal transition from $\mathrm{I}^{\mathrm{L}}$ to $\mathrm{I}^{\mathrm{H}}$ and have solved the crystal structure of the latter based on single-crystal diffraction data.

According to our data, $\mathrm{I}^{\mathrm{L}}$ and $\mathrm{I}^{\mathrm{H}}$ differ in the conformation of tolbutamide molecules. Ordered in $\mathrm{I}^{\mathrm{L}}$, the tolbutamide alkyl tail becomes disordered across the $\mathrm{I}^{\mathrm{L}} \Rightarrow \mathrm{I}^{\mathrm{H}}$ transformation, split over two positions. The torsion angle, C9-C10C11-C12, changes by $120^{\circ}$ for one position and by $75^{\circ}$ for the other. Three of the four alkyl tail atoms attract particular attention when considering this transition. The thermal ellipsoids of C10 and C12 increase significantly in size, while that of C11 splits into two ellipsoids with occupancies of 0.59(3) and $0.41(3)$. Despite this disordering, the space group remains unchanged across the $\mathrm{I}^{\mathrm{L}} \Rightarrow \mathrm{I}^{\mathrm{H}}$ transformation, and both the packing and hydrogen-bond framework remain largely unchanged. Only a slight displacement of neighboring molecules can be detected (Fig. 2).

Thermal studies of the $\mathrm{I}^{\mathrm{L}} \Leftrightarrow \mathrm{I}^{\mathrm{H}}$ transition at different heating/cooling rates (Fig. 3) show endothermic peaks on 


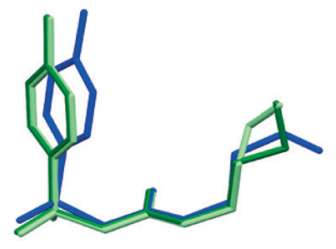

(a)

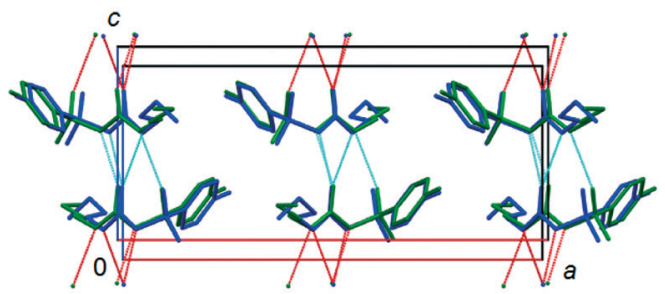

(b)

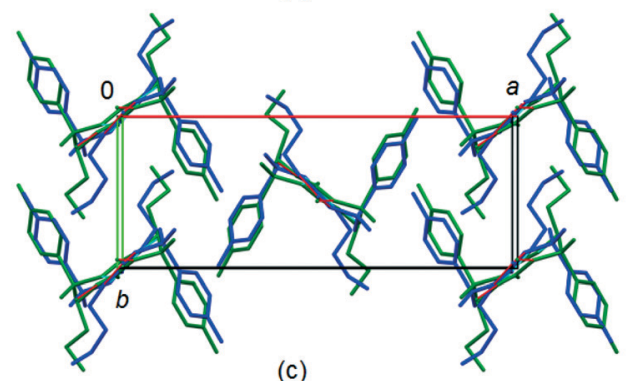

(c)

Fig. 2 Overlay of two tolbutamide molecules (a) and two tolbutamide crystal structures (without protons): (b) is the projection along axis $b$, (c) is the projection along axis $c$. Blue represents polymorph $\mathrm{I}^{\mathrm{L}}$, green represents $\mathrm{I}^{\mathrm{H}}$, and cyan and red dotted lines indicate hydrogen bonds.

heating and exothermic peaks on cooling. Usually, the onset temperature on heating is greater than that on cooling because of the thermal inertia in the measuring system. The greater the heating/cooling rate, the greater the thermal inertia and the difference between the onset points, with the onset temperature on cooling always being below the onset temperature on heating. Here, we have a completely different case when the onset temperature of $312.75 \mathrm{~K}$ on heating is less than that of $313.0 \mathrm{~K}$ on cooling with the smallest heating/cooling rates. Such a case is rather rare and can be

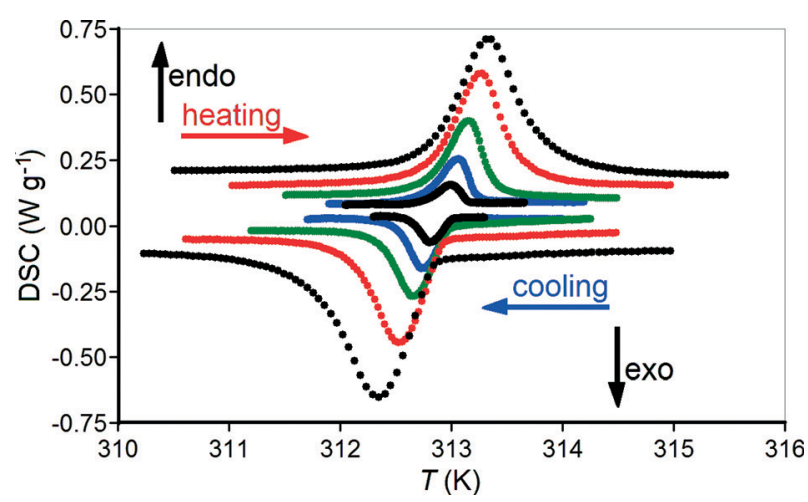

Fig. 3 DSC results for reversible $\mathrm{I}^{\mathrm{L}} \Leftrightarrow \mathrm{I}^{\mathrm{H}}$ transformation in tolbutamide on cycling heating/cooling with heating/cooling rates of $3,2,1,0.5$, and $0.2 \mathrm{~K} \mathrm{~min}^{-1}$ (top to bottom for heating; bottom to top for cooling). explained in terms of randomly distributed transition points among particles in the powder sample; different particles (microcrystals) transform from one polymorph to another at different temperatures. The integral thermal effect of a transformation in a powder appears as a normal distribution in accordance with the central limit theorem. This effect has been discussed for the thermal character of the irreversible $\gamma$ $\rightarrow \alpha$ transformation in glycine over a temperature range of approximately 430 to $445 \mathrm{~K}$ (Fig. 1 in ref. 28). The temperature interval of $0.25 \mathrm{~K}$ between the onset temperatures on heating and cooling for the reversible $\mathrm{I}^{\mathrm{L}} \Leftrightarrow \mathrm{I}^{\mathrm{H}}$ transformation in tolbutamide I powder is extremely narrow and indicates a mechanism without nucleation. Hasegawa et al. ${ }^{14}$ reported the transition point at $311 \mathrm{~K}$. Their DSC experiments were carried out at a heating/cooling rate of $10 \mathrm{~K} \mathrm{~min}^{-1}$, which is too high for accurate measurements of transition points. Furthermore, no information regarding the accuracy of the temperature calibration was reported. ${ }^{14}$

\section{Temperature-dependence of cell volume}

The volume per molecule for the three polymorphs of tolbutamide as a function of temperature is shown in Fig. 4. It becomes evident that the low-temperature phase in tolbutamide $\mathrm{III}^{2}$ ( $\mathrm{III}^{2}$ in ref. 17 and the "high $\mathrm{Z}^{\prime}$ crystal structure of form III" in ref. 16) is the result of a polymorphic transformation occurring between 125 and 150 K. The data in Fig. 4 allowed calculation of the difference in volume (corrected for thermal expansion) across polymorphic transformations, $\mathrm{I}^{\mathrm{L}} \Leftrightarrow \mathrm{I}^{\mathrm{H}}$ and III $^{2} \Leftrightarrow$ III, in tolbutamide (Table 2). For irreversible transformations, II $\Rightarrow \mathrm{I}^{\mathrm{H}}$, III $\Rightarrow \mathrm{I}^{\mathrm{H}}$, and IV $\Rightarrow \mathrm{I}^{\mathrm{H}}$, in tolbutamide, the increase in the normalized volume $(\Delta V / V)$ was calculated as the difference between the volumes of the initial (II, III, and IV) and resulting $\left(\mathrm{I}^{\mathrm{H}}\right)$ polymorphs. The corresponding values for chlorpropamide polymorphs are listed in Table 2 for comparison, with our data borrowed from..$^{5-10}$ The error in the

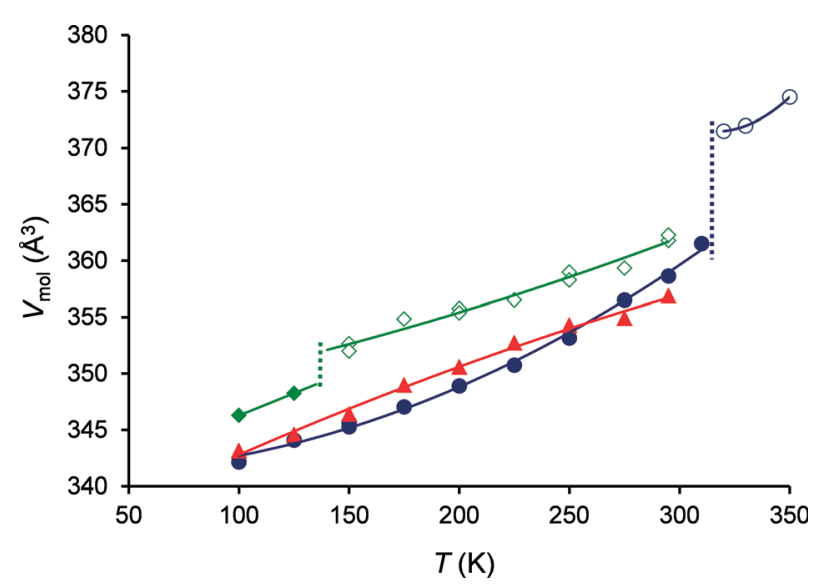

Fig. 4 The volume per molecule in various polymorphs of tolbutamide: blue filled circles $-\mathrm{I}^{\mathrm{L}}$, open circles $-\mathrm{I}^{\mathrm{H}}$, red triangles $-\mathrm{II}$, green open diamonds $-\mathrm{III}$, filled diamonds $-\mathrm{III}^{2}$. Solid lines are guides to the eye. Vertical dotted lines indicate the temperature of the polymorphic transition. 
Table 2 Relative change in the volume per molecule for transformations

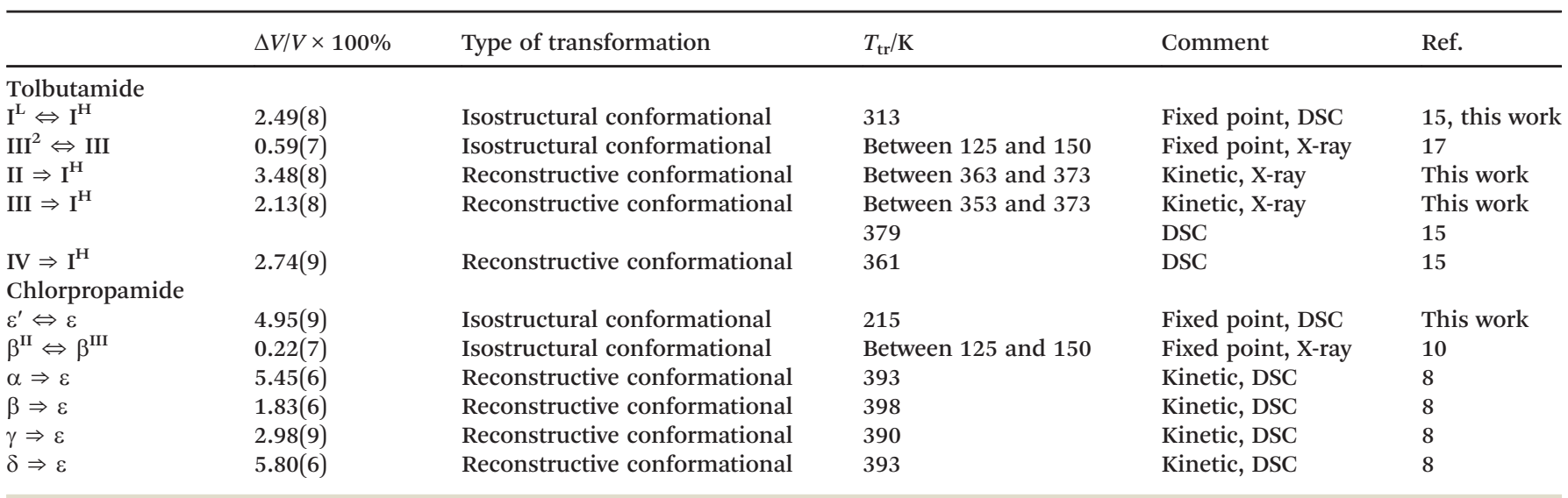

$\Delta V / V$ estimate is less than $\pm 0.2 \%$ for all data. There is no obvious difference in the $\Delta V / V$ changes between the isostructural and reconstructive transformations in either tolbutamide or chlorpropamide. The smallest volume change has been observed for the transformations that are accompanied by a change in the conformations of only a part of the molecules $\left(\beta^{\mathrm{II}} \Leftrightarrow \beta^{\mathrm{III}}\right.$ transition in chlorpropamide and $\mathrm{III}^{2} \Leftrightarrow \mathrm{III}$ in tolbutamide). Still, the isostructural transformations in tolbutamide differ in nature from those in chlorpropamide. Transformations $\mathrm{I}^{\mathrm{L}} \Leftrightarrow \mathrm{I}^{\mathrm{H}}$ and $\mathrm{III}^{2} \Leftrightarrow$ III in tolbutamide are accompanied by disordering of the alkyl tail atoms, in which the low-temperature form is ordered and the hightemperature one is disordered. In chlorpropamide, no disordering of the alkyl tails has been observed, either in the high-temperature or in the low-temperature forms.

Tolbutamide II does not show any polymorphic transformations across the temperature range 100 to $300 \mathrm{~K}$. Its normalized volume above $250 \mathrm{~K}$ is the smallest (and correspondingly its density is the largest) among all tolbutamide polymorphs.

\section{Anisotropy of thermal expansion in tolbutamide I}

The relative changes in the unit cell parameters versus temperature are shown for tolbutamide $\mathrm{I}^{\mathrm{L}}$ and $\mathrm{I}^{\mathrm{H}}$ in Fig. 5. Both polymorphs are orthorhombic and the principal axes of the strain ellipsoid coincide with the crystallographic axes. The thermal expansion character can be clearly defined by two regions: (1) conventional linear thermal expansion and (2) a singular change. The latter is observed at the transition point, while the remainder of the thermal expansion is characterized as (1). The largest conventional thermal expansion is observed along axis $a$, which is perhaps not surprising as this does not contain hydrogen bonds (Table 1, Fig. 2). The singular change at the transition point is also observed along axis $a$ (Fig. 5). Singular thermal expansion along other axes ( $b$ and $c$ ) (at the transition point) is negligible. At the transition point, parameter $b$ increases by over $1 \%$, while parameter $c$ decreases slightly. The hydrogen-bond chains are directed exactly along the $c$ axis (Fig. 2).
The temperature dependences of the donor-acceptor distances across hydrogen bonds are shown in Fig. 6. The $\mathrm{I}^{\mathrm{L}} \Leftrightarrow$ $\mathrm{I}^{\mathrm{H}}$ phase transition is accompanied by very interesting changes in the hierarchy of the bonds. The strongest and the shortest hydrogen bond, $\mathrm{N} 1-\mathrm{H} 1 \cdots \mathrm{O} 3$, remains unchanged, but the bifurcated hydrogen bonds, $\mathrm{N} 2-\mathrm{H} 2 \cdots \mathrm{O} 2$ and $\mathrm{N} 2-$ $\mathrm{H} 2 \cdots \mathrm{O} 3$, change. The distance $\mathrm{N} 2 \cdots \mathrm{O} 3$ increases and becomes longer than the distance $\mathrm{N} 2 \cdots \mathrm{O} 2$ in the hightemperature form $\mathrm{I}^{\mathrm{H}}$, while in the ambient-temperature form $\left(\mathrm{I}^{\mathrm{L}}\right)$ the distance $\mathrm{N} 2 \cdots \mathrm{O} 2$ was longer. Similar changes in the hydrogen bonds were seen in $\alpha$-chlorpropamide across its transformation to the high-pressure polymorph. ${ }^{11}$

\section{Isostructural conformational and single-crystal-to-single- crystal transformations}

We use the term 'isostructural' in this paper, as defined by Coles et al. ${ }^{29}$ to describe phase transitions without a major change in molecular packing, with particular emphasis on their relation to single-crystal to single-crystal phase

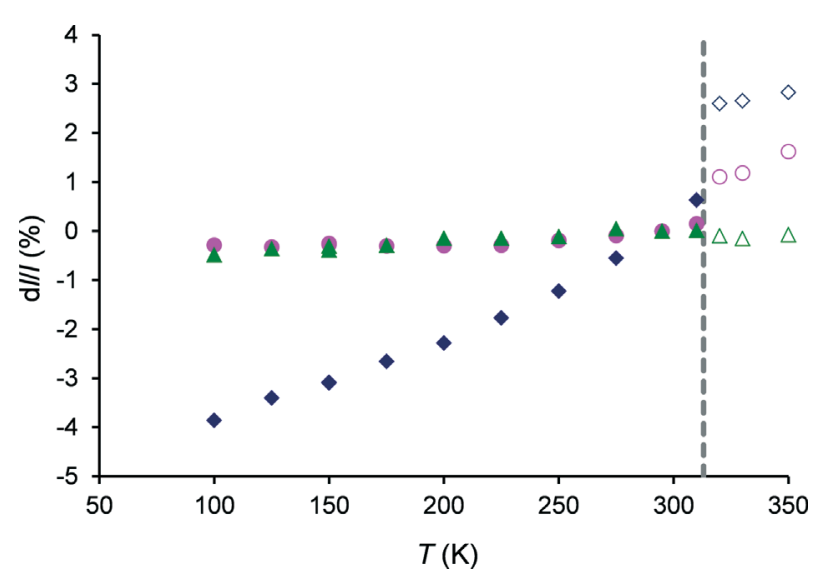

Fig. 5 The relative changes in the unit cell parameters versus temperature for polymorphs $\mathrm{I}^{\mathrm{L}}$ (filled symbols) and $\mathrm{I}^{\mathrm{H}}$ (open symbols): blue diamonds - along axis a, pink circles - along axis $b$, green triangles - along axis $c$. The vertical dotted line indicates a transition point at $313 \mathrm{~K}$. 


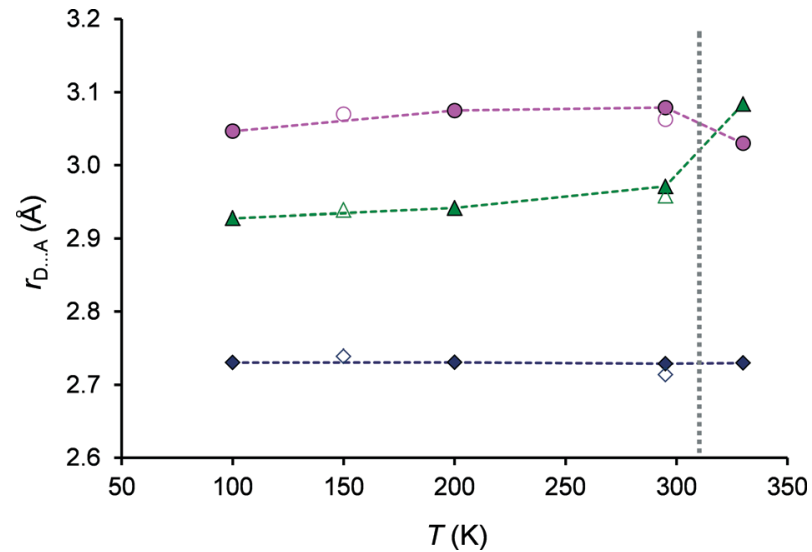

Fig. 6 Donor-acceptor distance for hydrogen bonds as a function of temperature for tolbutamide polymorphs $\mathrm{I}^{\mathrm{L}}$ and $\mathrm{I}^{\mathrm{H}}$ : circles are for $\mathrm{N} 2 \cdots \mathrm{O} 2$, triangles for $\mathrm{N} 2 \cdots \mathrm{O} 3$, and diamonds for $\mathrm{N} 1 \cdots \mathrm{O} 3$. Filled symbols show the results of this work and open symbols correspond to literature data. ${ }^{15}$ The lines connecting the points are guides to the eye only. The vertical dotted line indicates a transition point at $313 \mathrm{~K}$.

transitions. For many molecular crystals, reversible phase transitions that do not break single crystals have been reported. ${ }^{29-33}$ In this paper, we limit discussion to a comparison of the isostructural transformations in tolbutamide with those in chlorpropamide (Table 2). Transformations $\mathrm{I}^{\mathrm{L}} \Leftrightarrow \mathrm{I}^{\mathrm{H}}$ and $\mathrm{III}^{2} \Leftrightarrow \mathrm{III}$ in tolbutamide are indicated in Table 2 as being isostructural and conformational in nature. None of the hydrogen bonds are broken across these transformations; they are reversible, and single crystals preserve their shape and transparency. The transformation $\varepsilon^{\prime} \Leftrightarrow \varepsilon$ in chlorpropamide $^{9}$ is similar to the $\mathrm{I}^{\mathrm{L}} \Leftrightarrow \mathrm{I}^{\mathrm{H}}$ transformation in tolbutamide (both transformations are accompanied by a simultaneous change in the conformation of the alkyl tails of all molecules). The main difference between these two cases is quantitative, the volume change being $2.5 \%$ for tolbutamide and $5.0 \%$, twice as large, for chlorpropamide. This difference leads to a qualitative difference in the behavior of single crystals: a single crystal of $\varepsilon$-chlorpropamide is destroyed after several heating/cooling cycles across the $\varepsilon^{\prime} \Leftrightarrow \varepsilon$ transformation, whereas that of tolbutamide is preserved. When discussing the preservation of single crystals over the course of a phase transition, it is important to remember that the size of the crystal may be of crucial importance. For example, a glycine-glutaric acid co-crystal of $\sim 0.4 \mathrm{~mm}$ is preserved across a polymorphic transformation between 200 and $225 \mathrm{~K}$ with $\Delta V / V \approx 2.7 \%$, and the two phases can be studied by single-crystal X-ray diffraction, but a larger $(\sim 3 \mathrm{~mm})$ crystal used for DSC measurements breaks across this same transition. ${ }^{30}$

The $\mathrm{III}^{2} \Leftrightarrow$ III transformation in tolbutamide is similar to the $\beta^{\mathrm{II}} \Leftrightarrow \beta^{\mathrm{III}}$ transition in chlorpropamide ${ }^{10}$ (the two transformations are accompanied by a change in only part of the molecules). The main difference between these two cases is in the number of molecules changing their conformations. In tolbutamide, the alkyl tail turns in every third molecule, giving $Z^{\prime}=3$ in the low-temperature polymorph. In chlorprop- amide, the conformation changes in every fourth molecule, resulting in $Z^{\prime}=4$. As a direct result of these conformational changes, one of the unit cell parameters increases a whole number of times. Nevertheless, we also consider this type of transformation to be isostructural (to describe the INTERmolecular region, as opposed to the molecules themselves) because, while the changes in the formal mathematical description of symmetry are significant, they are accompanied by negligible changes in the packing of molecules.

\section{Isostructural conformational transformations versus reconstructive transformations}

The tolbutamide and chlorpropamide isostructural conformational transformations are also reversible at the macroscopic level. A single crystal can undergo a phase transition (or a series of phase transitions) with variations in $T$ and $P$ conditions, but will be exactly the same after the initial conditions are restored. In contrast, the initial single crystal is immediately lost (irreversibly) upon any reconstructive transformation, even if its crystal structure can be restored in the reverse transition. In many cases, after such a transformation, the initial phase (even as a powder) cannot be restored on returning to the initial conditions. For example, after determining the crystal structure of form $\mathrm{I}^{\mathrm{H}}$, we have proved (using in situ X-ray powder diffraction in a capillary on heating), that forms II and III of tolbutamide transform on heating into $\mathrm{I}^{\mathrm{H}}$ (II $\Rightarrow \mathrm{I}^{\mathrm{H}}$ and III $\left.\Rightarrow \mathrm{I}^{\mathrm{H}}\right)$, without any trace of the starting form in the high-temperature form (Fig. 7). On cooling, the high-temperature form transforms into $\mathrm{I}^{\mathrm{L}}$. These transformations ( $\mathrm{II} \Rightarrow \mathrm{I}^{\mathrm{H}}$ and $\mathrm{III} \Rightarrow \mathrm{I}^{\mathrm{H}}$ ) are thus irreversible.

The rate of a reconstructive transformation is often limited by nucleation. After a nucleus of the new phase reaches a critical size, it begins growing irreversibly. Comparative analysis of the initial and post-transformation structures shows that the reconstructive transformation cannot proceed without breaking bonds. For example, the infinite chains in

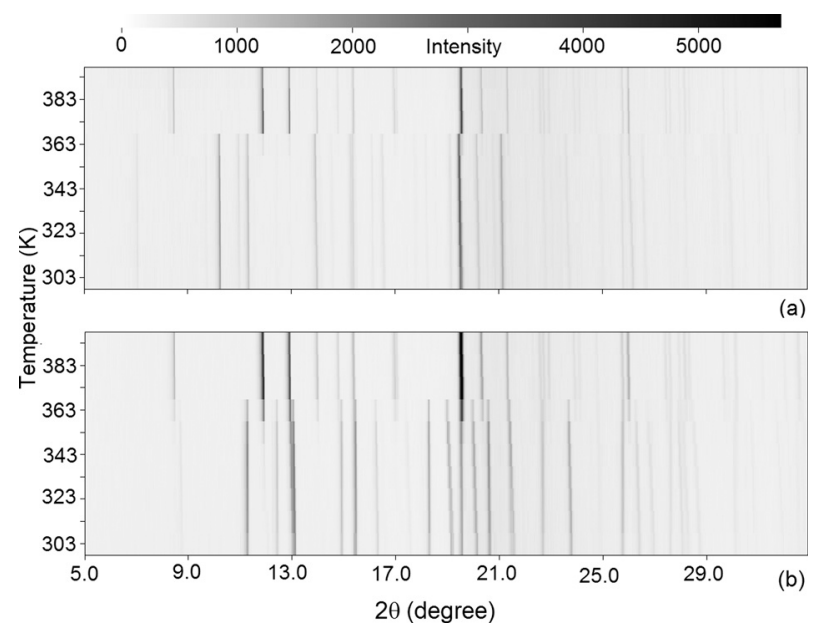

Fig. 7 X-ray powder diffraction patterns on heating tolbutamide form II (a) and form III (b) in situ. The temperature is that of the oven. At 383 $\mathrm{K}$, in both cases, the diffraction pattern corresponds to form $\mathrm{I}^{\mathrm{H}}$. 
all polymorphs of both chlorpropamide and tolbutamide, except tolbutamide II, are directed along a well-defined direction. In tolbutamide II, the chains that are formed by two of four symmetry-independent molecules (Ch1 and Ch2) run perpendicularly to the tapes formed by the remaining two symmetry independent molecules (Ch3 and Ch4). ${ }^{15}$ Because of this, even if the hydrogen-bond motifs (Scheme 1) are identical in all tolbutamide polymorphs, the $\mathrm{II} \Rightarrow \mathrm{I}^{\mathrm{H}}$ transformation cannot occur except via nucleation and subsequent recrystallization. The same is valid for chlorpropamide, where transformations $\alpha \Rightarrow \varepsilon$ and $\gamma \Rightarrow \varepsilon$ are not only accompanied by a change in space group, but also by a change in the symmetry of every second chain. Nucleation in reconstructive transformations is sensitive to thermal prehistory. In DSC measurements, the start of a reconstructive polymorphic transformation depends on the heating rate. ${ }^{34}$ It is obvious that no hysteresis occurs, as there is no reverse transformation. Reconstructive transformations have no well-defined transition temperature and can occur at any temperature beyond the limits of polymorphic stability. For example, the isothermal kinetics of the III $\Rightarrow \mathrm{I}^{\mathrm{H}}$ transformation in tolbutamide were studied at $65,70,75$, and $80{ }^{\circ} \mathrm{C}$ in. ${ }^{35}$ In isostructural transformations, the DSC peaks are reversible. Sometimes they are sharp peaks with hysteresis like that in a conventional first-order phase transition, ${ }^{30}$ and sometimes they appear as a triangular peak typical of a second-order phase transition (see $\beta^{\mathrm{II}} \Leftrightarrow \beta^{10}$ ). As for the $\mathrm{I}^{\mathrm{L}} \Leftrightarrow \mathrm{I}^{\mathrm{H}}$ transformation (Fig. 3), it surely resembles a first-order phase transition but, surprisingly, without hysteresis.

\section{Comparing the polymorphs of tolbutamide and chlorpropamide}

There are a number of common features between the polymorphic transformations of tolbutamide and chlorpropamide. For both compounds, there exists only one hightemperature polymorph, into which other forms transform before melting. However, each case is characterized by its peculiar features.

Of the five polymorphs of tolbutamide ( $\left.\mathrm{I}^{\mathrm{L}}, \mathrm{II}, \mathrm{III}, \mathrm{IV}, \mathrm{V}\right)$, three (II, III and IV) transform into form $\mathrm{I}^{\mathrm{H}}$ on heating below its melting point of $128{ }^{\circ} \mathrm{C}$. Form $\mathrm{V}$ is unstable at room temperature and transforms into $\mathrm{I}^{\mathrm{L}} .^{16}$ Depending on the heating conditions, form II can melt at its own melting point of 117 ${ }^{\circ} \mathrm{C}$, subsequently crystallizing exothermally to tolbutamide $\mathrm{I}^{\mathrm{H}}$, which then melts at $128{ }^{\circ} \mathrm{C},{ }^{15}$ but it can also transform into $\mathrm{I}^{\mathrm{H}}$ via a solid-state transition (see Fig. 7). Form $\mathrm{I}^{\mathrm{H}}$ is the most stable polymorph of tolbutamide at high temperatures. However, form $\mathrm{I}^{\mathrm{L}}$ is less stable than form III below $40{ }^{\circ} \mathrm{C},{ }^{36}$ transforming to form III in aqueous solution.

Of the five polymorphs of chlorpropamide $(\alpha, \beta, \gamma, \delta, \varepsilon)$, four $(\alpha, \beta, \gamma$, and $\delta$ ) transform into form $\varepsilon$ on heating. The latter melts at $128{ }^{\circ} \mathrm{C}$. For $\alpha$ and $\beta$, the temperature of their transformation into $\varepsilon$ depends on the heating rate and can overlap with the melting point of the product. In such cases, the endothermic start of the process is followed by an exo-

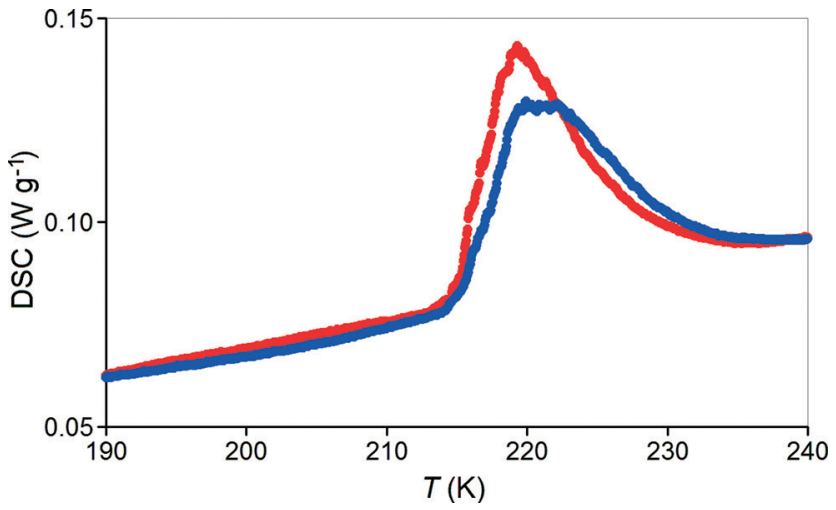

Fig. 8 DSC results for reversible $\varepsilon^{\prime} \Leftrightarrow \varepsilon$ transformation in chlorpropamide; the first (red) and second (blue) runs with the same powder sample $\left(6.9 \mathrm{mg}, 6 \mathrm{~K} \mathrm{~min}^{-1}\right)$.

thermic stage, subsequently resuming its endothermic behaviour. The $\varepsilon$ form is the most stable polymorph of chlorpropamide at high temperatures. However, it is less stable than the $\alpha$ form below room temperature, and the $\varepsilon \Rightarrow \alpha$ transformation occurs on storage at ambient conditions. This transformation was also observed on cryogrinding. ${ }^{37}$

The most stable high-temperature polymorphs of both tolbutamide $\left(\mathrm{I}^{\mathrm{H}}\right)$ and chlorpropamide $(\varepsilon)$ undergo reversible conformational isostructural transformations into their lowtemperature metastable daughter forms $\left(\mathrm{I}^{\mathrm{L}}\right.$ and $\varepsilon^{\prime}$, respectively), albeit at different temperatures: $313 \mathrm{~K}$ for $\mathrm{I}^{\mathrm{L}} \Leftrightarrow \mathrm{I}^{\mathrm{H}}$ (see Fig. 3) and $\sim 215 \mathrm{~K}$ for $\varepsilon^{\prime} \Leftrightarrow \varepsilon$ (see Fig. 8).

\section{Conclusions}

Structural investigation of the three polymorphs of tolbutamide (I, II, and III) over a wide temperature range (from 100 to $300 \mathrm{~K}$ for forms II and III and from 100 to $350 \mathrm{~K}$ for form I) allowed, for the first time, determination of the crystal structure of the high-temperature form, $\mathrm{I}^{\mathrm{H}}$, and calculation of the volume change $\Delta V / V$ for two isostructural transformations, $\mathrm{I}^{\mathrm{L}} \Leftrightarrow \mathrm{I}^{\mathrm{H}}$ and $\mathrm{III}^{2} \Leftrightarrow$ III. The reversible transformation, $\mathrm{I}^{\mathrm{L}} \Leftrightarrow \mathrm{I}^{\mathrm{H}}$, was found to be of the single-crystal to single-crystal type. The structure of $\mathrm{I}^{\mathrm{H}}$ differs from that of $\mathrm{I}^{\mathrm{L}}$ only in the conformation of the molecules. The exact temperature range of the $\mathrm{I}^{\mathrm{L}} \Leftrightarrow \mathrm{I}^{\mathrm{H}}$ transition in commercial powder was measured using DSC and was found to be extremely narrow (between $312.8 \mathrm{~K}$ at heating and $313.0 \mathrm{~K}$ at cooling). The temperature hysteresis was found to be less than the dispersion of the transition points for individual particles in the powder sample.

Comparison between polymorphic transformations in tolbutamide and chlorpropamide reveals much similarity. All transformations accompanied by a conformational change can be categorized into two types, isostructural and reconstructive. Reconstructive transformations are irreversible, affecting both the packing of molecules and molecular conformations. Isostructural transformations are also reversible at the macroscopic level and mainly affect the conformations of 
molecules, leaving the hydrogen bonds unchanged. Singlecrystal to single-crystal transformations are isostructural in nature.

\section{Acknowledgements}

The study was supported by Project No. V.44.3.4 of the Siberian Branch of the Russian Academy of Sciences. VAD acknowledges that his work was supported by state assignment project No. 0330-2016-004.

\section{References}

1 A. J. Cruz-Cabeza and J. Bernstein, Chem. Rev., 2014, 114, 2170.

2 A. Nangia, Acc. Chem. Res., 2008, 41, 595.

3 J.-P. Brog, C.-L. Chanez, A. Crochet and K. M. Fromm, RSC Adv., 2013, 3, 16905.

4 C. H. Koo, S. I. Cho and Y. H. Yeon, Arch. Pharmacal Res., 1980, 3, 37.

5 T. N. Drebushchak, N. V. Chukanov and E. V. Boldyreva, Acta Crystallogr., Sect. E: Struct. Rep. Online, 2006, 62, 04393.

6 T. N. Drebushchak, N. V. Chukanov and E. V. Boldyreva, Acta Crystallogr., Sect. C: Cryst. Struct. Commun., 2007, 63, 0355.

7 T. N. Drebushchak, N. V. Chukanov and E. V. Boldyreva, Acta Crystallogr., Sect. C: Cryst. Struct. Commun., 2008, 64, 0623.

8 V. A. Drebushchak, T. N. Drebushchak, N. V. Chukanov and E. V. Boldyreva, J. Therm. Anal. Calorim., 2008, 93, 343.

9 T. N. Drebushchak, Y. A. Chesalov and E. V. Boldyreva, Acta Crystallogr., Sect. B: Struct. Sci., 2009, 65, 770.

10 T. N. Drebushchak, V. A. Drebushchak and E. V. Boldyreva, Acta Crystallogr., Sect. B: Struct. Sci., 2011, 67, 163.

11 Yu. V. Seryotkin, T. N. Drebushchak and E. V. Boldyreva, Acta Crystallogr., Sect. B: Struct. Sci., Cryst. Eng. Mater., 2013, 69, 77.

12 K. A. Nirmala and D. S. Sake Gowda, Acta Crystallogr., Sect. B: Struct. Crystallogr. Cryst. Chem., 1981, 37, 1597.

13 J. D. Donaldson, J. R. Leary, S. D. Ross, M. J. K. Thomas and C. H. Smith, Acta Crystallogr., Sect. B: Struct. Crystallogr. Cryst. Chem., 1981, 37, 2245.

14 G. Hasegawa, T. Komasaka, R. Bando, Y. Yoshihashi, E. Yonemochi, K. Fujii, H. Uekusa and K. Terada, Int. J. Pharm., 2009, 369, 12.

15 S. Thirunahari, S. Aitipamula, P. S. Chow and R. B. H. Tan, J. Pharm. Sci., 2010, 99, 2975.
16 N. K. Nath and A. Nangia, CrystEngComm, 2011, $13,47$.

17 T. N. Drebushchak, N. A. Pankrushina and E. V. Boldyreva, Dokl. Phys. Chem., 2011, 437, 61.

18 T. N. Drebushchak, N. A. Pankrushina, A. N. Mikheev and M. K. A. Thumm, CrystEngComm, 2013, 15, 3582.

19 T. N. Drebushchak and E. V. Boldyreva. Our unpublished data on cooling of $\gamma$-, and $\delta$-polymorphs of chlorpropamide (100-298 K).

20 F. H. Allen, Acta Crystallogr., Sect. B: Struct. Sci., 2002, 58, 380.

21 Agilent, CrysAlisPro, 2010, Agilent Technologies Ltd, Yarnton, England.

22 G. M. Sheldrick, Acta Crystallogr., Sect. A: Found. Crystallogr., 2008, 64, 112.

23 G. M. Sheldrick, SHELXL2014, University of Göttingen, Germany.

24 L. J. Farrugia, J. Appl. Crystallogr., 2012, 45, 849.

25 L. J. Farrugia, J. Appl. Crystallogr., 1997, 30, 565.

26 STOE \& Cie GmbH, WinXPOW, 2011, STOE \& Cie $\mathrm{GmbH}$, Darmstadt, Germany.

27 C. F. Macrae, I. J. Bruno, J. A. Chisholm, P. R. Edgington, P. McCabe, E. Pidcock, L. Rodriguez-Monge, R. Taylor, J. van de Streek and P. A. Wood, J. Appl. Crystallogr., 2008, 41, 466.

28 E. V. Boldyreva, V. A. Drebushchak, T. N. Drebushchak, I. E. Paukov, Y. A. Kovalevskaya and E. S. Shutova, J. Therm. Anal. Calorim., 2003, 73, 419.

29 S. J. Coles, T. L. Threlfall and G. J. Tizzard, Cryst. Growth Des., 2014, 14, 1623.

30 B. A. Zakharov, E. A. Losev, B. A. Kolesov, V. A. Drebushchak and E. V. Boldyreva, Acta Crystallogr., Sect. B: Struct. Sci., 2012, 68, 287.

31 E. J. Chan, A. D. Rae and T. R. Welberry, Acta Crystallogr., Sect. B: Struct. Sci., 2009, 65, 509.

32 C. H. Gorbitz, J. Phys. Chem. B, 2011, 115, 2447.

33 C. H. Gorbitz, F. Alebachew and V. Petricek, J. Phys. Chem. B, 2012, 116, 10715.

34 V. A. Drebushchak, T. N. Drebushchak and E. V. Boldyreva, J. Therm. Anal. Calorim., 2013, 113, 419.

35 T. Umeda, N. Ohnishi, T. Yokoyama, T. Kuroda, Y. Kita, K. Kuroda, E. Tatsumi and Y. Matsuda, Chem. Pharm. Bull., 1985, 33, 2073.

36 E. L. Rowe and B. D. Anderson, J. Pharm. Sci., 1984, 73, 1673.

37 T. N. Drebushchak, A. A. Ogienko and E. V. Boldyreva, CrystEngComm, 2011, 13, 4405. 